Otologists"), it is impossible not to be impressed with the long list of names of men in every country who, as far as we are able to judge, are as conscientious and honourable workers as may be found in any branch of this or any other profession. The result of their work is seen in the triumphs of modern laryngology, rhinology, and otology, and it is difficult to see how criticism openly expressed can do any permanent harm. As for individual workers, it may be safely stated that those who have the keenest sense of responsibility, and whose work is guided by healthy introspection, will be least troubled with such fears.

It would be as unwise. as it would be uncharitable to assume that there are many workers in our special department who intentionally over-operate. If there is a minority, it may be severely left to find-and surely will find-its true level. That there may be those who, with the best intention, err by overoperating we admit, but the tendency of our special department is onward, and its work is so great that we can welcome criticisms, believing as we do that, after all momentary feelings and expressions to which a controversy gives rise have expended themselves, nothing can alter or materially affect its progress.

May we venture to hope at the beginning of this year that less will be heard of controversial matters, and that there will be no abatement of that work in this and every civilized country, which is surely and steadily adding to the great and honourable history of our special department.

\title{
PARAFFIN INJECTIONS IN CASES OF SUNKEN NOSE.
}

AN interesting communication on this subject was read by Mr. Stephen Paget before the Clinical Society of London at one of its most recent meetings. In it he gave the result of his experiences in twenty-five cases; of these, eight were female and seventeen male, the age of the youngest being nineteen and of the oldest fifty-two. In two of his cases the nose was not only somewhat sunken, but also crooked, and had to be straightened with Walsham's forceps; in several there was perforation of the cartilaginous septum, and in one also extensive destruction of the roof of the mouth; ozæna was present in one case. As regards the cause, in about one half this was congenital or the result of disease, and in the other half, injury. In a few cases some operation had been done to remedy the deformity, and had failed. In twelve of his cases Mr. Paget used Eckstein's paraffin, which 
melted at the very high temperature of $136^{\circ} \mathrm{F}$.; but he expressed the conviction that this had no advantage over paraffin melting at 25 or 30 degrees lower, while it had obvious disadvantages, being very hard to work with, setting with most embarrassing rapidity, and being so hot that there was risk of burning the tissues. Gersuny's paraffin, which melts at $104^{\circ}$, he had also given up, partly owing to the possibility that it might yield if the patient had, as possible in malaria or typhoid, a temperature of $105^{\circ}$, and also because the heavy pressure on the paraffin occasioned by the contraction of the skin was apt to lead to its compression and displacement. The paraffin that he recommended most strongly was one melting at a temperature of $111^{\circ}$. The writer of the present article, having selected this particular paraffin, on Mr. Paget's recommendation, for use in a case recently under his care, can from his experience confirm the good opinion expressed of it.

Mr. Paget pointed out that whatever paraffin was used a slight shrinkage was inevitable, and that no disappointment must be felt at the occurrence. A further small injection could be effected after an interval of a week without any other anæsthetic than cocaine.
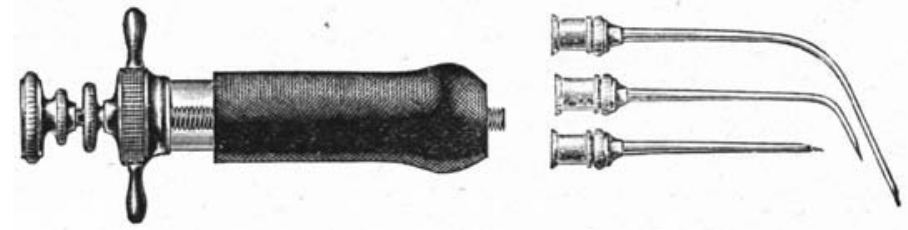

The syringe ${ }^{1}$ employed is Eckstein's, but fitted with a short, straight needle. It has a screw-nut on its piston-rod, so that the amount of paraffin injected at each compression can be exactly regulated. There is a movable cover of indiarubber, which retains the heat sufficiently well.

Everything is prepared as for a major operation, and a general anæsthetic should be given. The paraffin, previously melted in its pot, is put ready with the syringe in a water-bath, kept-as tested from time to time by the thermometer-at a temperature of about $120^{\circ} \mathrm{F}$. The skin may be slightly nicked, so that the needle may be the more easily introduced. Mr. Paget is not in favour of freeing the skin by means of a tenotomy knife, as in a case in which he did so he punctured the mucous membrane. Five or six c.c. of paraffin are drawn up into the syringe, which

1 The syringe here described is supplied by Mr. F. A. Rogers, Chemist, Oxford Street, W., who has also prepared paraftin of the required melting-point. 
is then held in the water-bath, while the screw-nut on the shaft is adjusted. When all is ready the assistant makes pressure with his fingers and thumbs to prevent diffusion of the paraffin up over the forehead or into the orbital tissues. The syringe is then taken out of the bath, its point is held in boiling water for two or three seconds and is then introduced well under the skin, below the level of the bridge of the nose, a little to one side of the middle line, and directed upwards. The injection is made at the rate of about 1 c.c. every ten seconds. Two or three separate punctures are sometimes necessary. The paraffin mass must then be moulded, and squeezed firmly and steadily till it becomes rigid. The punctures are sealed with collodion and a mask of wet lint is placed over the nose. Care must be taken that the patient does not knock his nose about during the period of restlessness preceding his return to complete consciousness, but as soon as he has settled down he may be given a hand-mirror and may mould the paraffin for himself.

Complications only occurred in a few of the cases, in which the paraffin employed melted only at $136^{\circ}$. The cases in which the disfigurement was greatest were those which gave the best results. It is easy, concludes Mr. Paget, in nine eases out of ten, to improve a badly sunken nose so that it shall be at least unnoticeable, and shall not prevent its owner from getting employment or from getting married, and shall not compel him to be laughed at or pitied or suspected of syphilis wherever he goes.

Dr. Scanes Spicer at the same meeting narrated his experience in dealing with the first case treated by this method in this country. He used a paraffin which melted at a much lower temperature, and some escaped into the orbits. This was, however, removed, and the ultimate result, as shown by casts taken before and after the operation, was eminently gratifying.

Success can only be obtained by careful attention to details, which experience alone can teach. The experience accumulated by Dr. Scanes Spicer and Mr. Paget as here briefly narrated, will, we trust, be of value to our readers.

D. G. 